\title{
LA DEPORTIVIDAD COMO CATEGORÍA MORAL: LAS PROPUESTAS DE KEATING Y FEEZELL
}

\author{
Raúl Francisco Sebastián Solanes \\ Universidad de Valencia \\ Facultad de Filosofía y CCEE \\ raul.sebastian@uv.es
}

Fecha de recepción: Enero 2018

Fecha de aceptación: Abril 2018

\section{http://dx.doi.org/10.15366/citius2018.11.1.004}

Resumen:

En el presente artículo nos proponemos rescatar la importancia de ver la deportividad como categoría moral desde la aportación realizada por Keating en su artículo de 1964. Ampliando la propuesta pionera de Keating con la realizada por Feezell se analizan los pro y contra de la distinción entre deporte y atletismo. Centrándonos en la importancia de ver la deportividad como una categoría moral que se aplica al deporte y al atletismo de forma homogénea, viendo que por encima del énfasis de la victoria se impone el trabajo cooperativo y en equipo, sin el cual no podría existir un comportamiento ético en deporte.

Palabras clave: Deportividad, ética, Keating, Feezell.

Title: SPORTSMANSHIP AS A MORAL CATEGORY: THE PROPOSALS OF KEATING AND FEEZELL

Abstract:

In this article I propose to rescue the importance of seeing sportsmanship as a moral category from the contribution made by Keating in his 1964 article. Expanding the pioneering proposal of Keating with the realization of Feezell, seeing against the distinction between sport and athletics. Focusing on the importance of seeing sportsmanship as a moral category that applies to sport and athletics in a homogeneous way, seeing that above the emphasis of victory, cooperative work is imposed and in a team without which there could be no ethical behavior in sport.

Key words: sportsmanship, ethics, Keating, Feezell.

\section{Introducción}

Ya el barón Pierre de Coubertin había hablado de una sana filosofía del deporte, vinculada al papel pedagógico y ético que puede trasmitir la práctica del deporte y cuyo trasfondo debe caracterizar al moderno Olimpismo. En España José Ortega y Gasset publicó en 1924 en su ensayo «El origen deportivo del Estado» abrió un campo de reflexión sobre el deporte desde la perspectiva filosófica. Así lo ha hecho constar Jesús Ilundain, quien en 2014 publicó un interesante artículo en la revista Sport, Ethics and Philosophy con el título «José Ortega y Gasset: Exuberant Steed».

Tuvo que transcurrir un tiempo para consolidar la conocida como «filosofía del deporte» que cobró actualidad como una subdisciplina de la filosofía formal o mejor dicho, académica (McNamee, 2007, pp. 1-6). Un acontecimiento importante para el surgimiento de la filosofía del deporte fueron las publicaciones de Bernard Suits. En efecto, la consolidación de una filosofía del deporte tomó impulso gracias a las publicaciones realizadas por Suits, como su 
importante artículo «The elements of sport» publicado en 1973. En dicho texto, se relacionó deporte con juego proponiendo cuatro elementos que nos ayudarían a definir qué es el deporte en tanto que juego. Dichos elementos son: que todo juego es meramente un juego de habilidad; es un tipo de habilidad física; que el juego tiene una gran variedad de vertientes y, por último, que esta variedad de vertientes logran cierto nivel de estabilidad. De este modo con Suits (2007) se impulsaba una tendencia de pensar y plantear el deporte desde un enfoque filosófico analizando filosóficamente los términos más destacados del variado mundo del deporte. Como señala Francisco Javier López Frías (2016, p. 51), de singular importancia para la historia de la ética del deporte es el libro de Suits (2005, pp. 1-2) publicado en 1978 y reimpreso en 2005 con el título The Grasshopper: Games, Life and Utopia. En este libro Suits tiene como objetivo proporcionar una definición tradicional de juegos para contrarrestar la posición antidefinicionista que Ludwig Wittgenstein (2001) había adoptado en su obra Philosophical Investigations.

En EEUU la American Philosophical Association de Boston, fundó el 28 de diciembre de 1972 la Philosophic Society for the Study of Sport (PSSS) con el principal respaldo y esfuerzo del profesor Warren P. Fraleigh de la State University of New York. Fraleigh es considerado, a día de hoy, uno de los pioneros y principales representantes del estudio filosófico y ético del deporte. Este prestigio no sólo se debe a la fundación de la PSSS, sino también a la publicación en 1984 de su libro Right actions in sport. En la referida obra, Fraleigh desarrolló su propuesta de ética del deporte que inaugura el denominado Formalismo ético en deporte. El primer presidente de esta nueva Sociedad filosófica (PSSS), fue el profesor Paul Weis de la Catholic University of América que también ha contribuido a este campo con importantes publicaciones y antologías de textos sobre el tema, especialmente con su obra Sport: A philosophical inquirí (1969). La PSSS ocupó el protagonismo a nivel mundial durante un largo tiempo debido precisamente a su carácter pionero, al ofrecer un enfoque filosófico en el estudio del deporte. A partir de 1999 la PSSS pasó a llamarse definitivamente como International Association for Philosophy of Sport y añadió la diversidad regional de los miembros que la componen. Desde esta Asociación se empezó a publicar The Journal for the Philosophy of Sport.

En el mismo año 1972, tuvo lugar otro acontecimiento decisivo que marcó la historia de la filosofía y ética del deporte contemporáneo. Ese mismo año, con motivo de la reunión de intercambio filosófico organizada por la Facultad de Arte y Ciencias de la State University of New York, se reunieron importantes figuras del pensamiento contemporáneo. En las actas de aquella reunión aparecieron publicados importantes textos de los futuros representantes de la ética del deporte como Paul Weis, Warren P. Fraleigh o Kretchmar junto con una importante publicación de Alasdair MacIntyre (1972, pp. 5-13). La coincidencia de unir los trabajos de estos autores tuvo como resultado la decisiva influencia que marcó en adelante el pensamiento filosófico de MacIntyre en las propuestas de filosofía y ética del deporte, especialmente en el pensamiento de Fraleigh y su obra Right actions in sport. Desde entonces, un variado grupo de escritores eclécticos inspirados por Alasdair MacIntyre y, sobre todo desde la publicación de After Virtue, en 1981, se alejaron de una visión analítica, a-histórica y asocial de entender el estudio del deporte, pero también se alejaron del tratamiento deontológico de la ética del deporte. Sobre todo, de aquellos planteamientos de construcciones de teorías del juego limpio y se inclinan hacia una teoría de la virtud y hacia la visión de una ética del deporte entendida desde el ámbito de las virtudes y de una práctica virtuosa (McNamee, 2007, pp. 1-6).

También es cierto que, durante la década anterior, concretamente en el año 1964, había aparecido algún artículo como el de J. Keating, titulado: «Sportsmanship as a moral category», en el que desde el ámbito de la filosofía académica se hablaba de «deportividad» cómo categoría moral (Keating, 1964, p. 25-35). En este artículo Keating denuncia que la «deportividad» ha sido una categoría ignorada y en cierto modo desatendida por buena parte de 
filósofos y teólogos. ${ }^{1}$ Lamentablemente este texto ha pasado a veces desapercibido, cuando en realidad juega un papel importante en la filosofía y ética del deporte, ya que ofrece una valoración moral al fenómeno deportivo. Además, su importancia se da en las críticas que autores como Peter J. Arnold o Randolph M. Feezell le dedican en sus escritos y a los que dedicaremos atención en este artículo.

\section{Breve historia de la deportividad como categoría moral}

En la reciente historia de la ética del deporte, encontramos textos que han marcado un hito, un punto de arranque hacia nuevos horizontes de investigación y producción intelectual. Este es el caso de James W. Keating quien en 1964 publicó un artículo titulado: «Sportsmanship as a moral category» en el que entiende la deportividad como virtud; es decir como una categoría moral. Ya la propuesta del barón Pierre de Coubertin había planteado la utilización educativa y moralizante del deporte como transmisión de valores, germen del moderno olimpismo y de la sana filosofía del Movimiento Olímpico (Coubertin, 1973). Por ello, pese a que la posición de Keating ha sido muy criticada -por razones que luego analizaremos- y superada en buena parte por sus sucesores inmediatos, lo cierto es que su aportación al estudio de la ética del deporte debe de ser considerada importante y pionera ya que a él se debe el impulso del pensamiento que entendió el deporte desde la perspectiva de la ética de la virtud. De este modo es deudor o continuador de la buena filosofía expuesta por Pierre de Coubertin.

Keating es consciente de que la «deportividad» ha sido una categoría ignorada y en cierto modo desatendida por buena parte de filósofos y teólogos. Pese a que la deportividad siempre ha pretendido tener relevancia moral, lo cierto es que su lugar entre las virtudes morales ha sido incierto. Sí podemos encontrar -casi de manera marginal- algunas afirmaciones por parte de importantes personajes de la vida cultural y política, que dieron a la deportividad cierta carga moral. Ya el filósofo francés y Premio Nobel de Literatura en 1927, Henri Bergson, en una entrevista concedida el 15 de junio de $1912,{ }^{2}$ confesaba su profunda convicción acerca del valor inconmensurable del deporte. Bergson sostenía que estimaba la confianza en sí mismo que el deporte procura a sus participantes, manifestando, además, que creía en un renacimiento moral de Francia a través de la práctica deportiva. Otro ejemplo es el caso de Albert Camus Premio Nobel de literatura en 1957 quien afirmó que en el deporte aprendió todo lo que sabía sobre la ética (Camus, 1951, p. 198), o el caso de Robert C. Clothier, presidente de la Rutger University que consideraba irrelevante quien escribiera las leyes de una sociedad siempre y cuando existiera una buena deportividad, ya que la buena deportividad es la que controla la conducta y regula las relaciones entre los hombres (Leahi, 1951, p. 198). También Lyam Brysol (1947, p. 130) de la Universidad de Columbia, denunciaba la falta de atención que se le ha dado a la deportividad, pues para él la deportividad viene a ser una forma de iluminación y la virtud sin la cual es imposible la democracia y la libertad. También lo podemos apreciar en los planteamientos del barón de Coubertín que se adelantó a su tiempo afirmando que el deporte era un instrumento moralizante, educador y transformador de la sociedad. Más aún, pues su filosofía olímpica une ética con estética, afirmando que

«La idea olímpica es a nuestros ojos la concepción de una avanzada cultura muscular, apoyada, por un lado, en el espíritu caballeresco que ustedes tan graciosamente llaman fair play, y por

\footnotetext{
${ }^{1}$ Pese a que Keating denuncie la falta de interés que se ha concedido al deporte desde el ámbito filosófico y el teológico, también es cierto que reconoce que algunos importantes representantes del mundo de la filosofía y del pensamiento en general han mostrado cierto interés por el importante papel del deporte. Así, por ejemplo, destaca a Albert Camus Premio, Nobel de literatura en 1957, quién llegó a afirmar que en el deporte aprendió todo lo que sabe sobre ética. Véase. Camus. A. (1951). Resistance, Rebellion and Death. New York: Alfred A. Knopf, Inc. Pág. 198.

${ }^{2}$ Bergson, H. (1912). Le Gaulois littéraire, citada por Carretón, P. (1985), en Les fêtes du corps. Université de Saint Etienne. Pág. 19.
} 
otro, en la noción estética, en el culto de lo que es bello y agraciado». (De Coubertin, 1973, pp. 37-38).

Así se cumple la célebre sentencia del profesor José María Valverde: Nulla aesthetica sine ethica.

La propuesta de Keating reabrió un importante campo de investigación que fue seguido por otros intelectuales que, aunque superen y critiquen a Keating, han sabido reconocer el importante papel que ha sabido hacer al introducir la deportividad como virtud y como categoría moral. Este aspecto, si bien le hace continuador del pensamiento de Coubertin, pero dejando su impronta personal y original al respecto.

\section{Keating ante el problema de la definición entre deporte, atletismo y deportividad}

La «Carta europea del deporte», que se hizo pública en el año 1992, define deporte como: todo tipo de actividades físicas que, mediante una participación, organizada o de otro tipo, tengan por finalidad la expresión o la mejora de la condición física o psíquica, el desarrollo de las relaciones sociales o el logro de resultados en competiciones de todos los niveles. En el texto de Keating nos situamos en un período previo a esta definición que actualmente goza de respaldo internacional, por lo que su esfuerzo imprime ya de entrada un mérito. Keating sabe que a lo largo de la historia se han hecho intentos de definir la deportividad y el deporte, el problema es que estos intentos, en lugar de arrojar luz, lo que han hecho es oscurecer más el problema de la definición del concepto de deportividad.

Si recurrimos al diccionario encontramos que la deportividad se define como la conducta que mantiene el deportista en el terreno de juego. Ésta cuestión nos llevaría a ver qué es un deportista -siguiendo la definición de deportista ofrecida por el diccionario- es alguien que está interesado o que toma parte en el deporte. Pero entonces, tendríamos que ver qué es el deporte. En este punto Keating recurre a la aportación que ha hecho Webster a este respecto, entendiendo que el deporte es aquello que nos desvía de la preocupación cotidiana y nos conduce hacia la alegría. Por ello, el deporte es una diversión, una recreación y un pasatiempo. Para Keating (1964, p. 27) es aquí donde nos encontramos cara a cara con el problema básico que ha distorsionado y adolece la mayoría de los debates sobre la deportividad, se trata del problema de la definición del término deporte.

Ciertamente, el término deporte ha sido aplicado indistintamente a diferentes tipos de comportamiento humano sin especificar. Allen Guttmann en su célebre trabajo From ritual to record: the nature of modern sport publicado en 1978 clasifica en siete las características del deporte moderno, a saber: secularismo, principio de igualdad, especialización, racionalización, burocratización, cuantificación y espectáculo de masas (Guttmann, 1978), De este modo encontramos que el deporte se aplica tanto para referirse a la actividad que tiene como objetivo proporcionar diversión y alegría ayudándonos a salir de los problemas que nos acechan a diario, como para referirse a la lucha agonística en el terreno de juego, como excusa para mostrar las habilidades físicas ante un grupo y obtener la victoria. Por tanto -según Keating- el verdadero problema de la deportividad reside en la ambigüedad y amplitud de situaciones que encontramos a la hora de definir y aplicar el término deporte.

Para evitar este tipo de problemas y poder definir la deportividad en términos morales, Keating $(1964$, p. 28) introdujo una distinción entre deporte y atletismo, entendiéndolos como dos términos vinculados por un nexo común, pero que se aplican a actividades y objetivos diferentes. Para Keating el deporte es una especie de desviación que tiene como finalidad más inmediata la diversión, el placer y el deleite de sus participantes. El deporte se caracteriza 
también por un espíritu de moderación y generosidad, además de una actitud cooperativa antes que competitiva. Por el contrario, el atletismo es esencialmente una actividad competitiva cuya finalidad consiste en obtener la victoria en el terreno de juego y que se fundamenta por cultivar el espíritu de dedicación, el sacrificio y la intensidad.

Esta distinción será clave para entender la deportividad como virtud y categoría moral y resuelve, a decir de Keating, los problemas que se seguían de una definición tan ambigua como la que se ha dado sobre el deporte, demostrando la complejidad de hallar una definición homogénea. En efecto, el deporte moderno se coloca a pleno título dentro de las instituciones sociales, constituyendo un sistema de reglas que son establecidas por la máxima instancia en el mundo deportivo que es el Comité Olímpico Internacional, trasmitiendo unos valores, contribuyendo a controlar, gestar y encauzar los diversos conflictos presentes en los grupos sociales. Representa además un completo "soto-sistema" social que interactúa entre las agencias de socialización primarias (familia) y las secundarias (escuela, iglesia...) lo que le concede una función de tipo socio- emocional (Dell, Aquila; Zurla, 2005, 13).

\section{Deportividad como virtud en la perspectiva de Keating}

Desde el punto de vista de Keating, la deportividad no puede entenderse simplemente como un conjunto de cualidades morales en las que se incluya un código de comportamiento especializado, pues la deportividad es también una actitud, una postura y una manera de interpretar lo que de otro modo sería un mero código legal. La preocupación que muestra de Keating es de carácter moral y se refiere a los hábitos o cualidades esenciales que caracterizan al participante como deportista.

En efecto, en el caso del deporte, la conducta y actitud del deportista influirán necesariamente en el desarrollo del encuentro deportivo. En consecuencia el proyecto principal del deporte no debe de ser el de ganar el partido a toda costa, pues el propósito y meta del deporte debe de ser el de hacer pasar un buen rato a sus participantes con independencia de proclamarse vencedor de la competición deportiva. Resulta esencial que el deportista desarrolle cualidades morales tan loables como el coraje, el autocontrol, la cooperación y un espíritu saludable de búsqueda del honor, pero sobre todo deberá poseer dos ingredientes fundamentales en su conducta que son la generosidad y la magnanimidad, pues estas dos son las que fomentan el esfuerzo cooperativo, para que la actividad nos lleve del placer a la alegría.

Keating (1964, p. 29) afirma que todas las fórmulas que componen el código de la deportividad se derivan de una máxima moral única que dice: «compórtate de tal manera, que aumente en lugar de que disminuya el placer que se encuentra en la actividad, tanto en tu persona como en la de tus compañeros». Esto demuestra que el código que rige el deporte debe ser sustancialmente diferente a un código legalista, como el que es utilizado por los tribunales de justicia o los abogados. El código del deporte tiene como objetivo principal el de proteger y cultivar el buen estado de ánimo y fomentar el carácter festivo característico de este tipo de actividad humana, cuya única finalidad debe de ser la de proporcionar una diversión agradable a sus participantes.

Para Keating, la competición es una forma de lucha entre dos partes que buscan un único objetivo. Por ello, el deporte no debe entenderse como una competición, sino como el esfuerzo cooperativo que nos permite pasar de un placer inmediato a la alegría, que se encuentra en la propia actividad deportiva; en consecuencia el deporte se entiende mejor en términos de generosidad, exaltación y alegría. Por eso, la actividad deportiva no debe ser competitiva sino cooperativa. En este punto, discrepo totalmente de la opinión de Keating, pues considero que el carácter competitivo es fundamental en todo tipo de práctica deportiva, ya que le da un carácter 
de mayor emoción al encuentro, lo que no tiene que ir reñido con el espíritu de cooperación que también creo que es esencial para el deporte, junto con su lado lúdico y jocoso.

\section{La deportividad aplicada al atletismo}

Según Keating los problemas surgen cuando nos pasamos del deporte al atletismo, pues nos percatamos de que la forma de entender la deportividad da un cambio drástico. Ya no se concibe la deportividad como la mutua relación de generosidad y magnanimidad, que permite un esfuerzo cooperativo que posibilita pasar del placer a la alegría, ya que lo importante para el atleta no es la cooperación y la alegría, pues el atleta en el fondo está demandando la posesión exclusiva del éxito y la victoria, que sólo podrá compartir con sus compañeros de equipo, nunca con sus oponentes.

Por este motivo, la esencia de la deportividad aplicada al caso del atletismo consiste en la práctica de la justicia bajo las condiciones más difíciles, pues su objetivo no es la cooperación que nos permita pasar un buen rato, sino que es la lucha que nos permita obtener la victoria (Keating, 1964, p. 32).

La paradoja de la deportividad -aplicada al atletismo- radica en que se exige al atleta que mantenga una actitud imparcial ante la competición, mostrando una actitud modesta ante la victoria y de imparcialidad ante la derrota. El atleta debe ser capaz de mantener la compostura en cualquier situación, mostrando así su profesionalidad. Si pierde, deberá tomárselo lo más calmado posible, demostrando autocontrol ante la adversidad y si gana, procurará no hacer demasiado alarde de su victoria ante su rival, ya que con un simple apretón de manos se demuestra que no ha habido una mala voluntad.

Obviamente uno de los principales problemas que atraviesa el atletismo profesional está relacionado con la ganancia económica. Es evidente que en el atletismo profesional, la alta calificación de los encuentros y el mayor número de victorias son esenciales para obtener el éxito financiero; además, en muchas ocasiones la derrota se traduce en un desempleo forzoso para el atleta profesional, ${ }^{3}$ por ello es normal que en el atletismo los competidores vean a sus oponentes como los hombres que pueden privarles de su sustento para vivir, lo que viene a dificultar un comportamiento virtuoso en la práctica del atletismo. Por tanto, resulta evidente según Keating- que existen diferencias cuantiosas entre el comportamiento que mantiene el deportista y el atleta.

En efecto, el deportista pretende alcanzar una situación de placer en el terreno de juego, por ello no duda en cooperar con su oponente para alcanzar este objetivo; sin embargo, al atleta no se le permite ninguna prueba de error, pues un error podría dar al traste con su carrera profesional.

Ahora bien, el sentido de «fair play» se entiende en un sentido más amplio que la mera adhesión de los participantes a la norma escrita, ${ }^{4}$ pues resulta evidente que existe un espíritu del

\footnotetext{
${ }^{3}$ Recuerdo a este respecto el caso de Meho Kodro, que en 1991 entre en la Liga de fútbol española como jugador de la Real Sociedad. Debido a su buen juego en 1997 fue fichado por el FC Barcelona que pagó por él 700 millones de pesetas. Durante su período como jugador del Barcelona su rendimiento en el terreno de juego disminuyó, hecho que se debía en parte a las diferentes lesiones físicas que recibió y a su frágil estado psicológico, debido a su preocupación por la guerra en Yugoslavia, su país de origen en donde residía gran parte de su familia y amigos. Este bajo rendimiento precipitó su salida inmediata del FC Barcelona.

${ }^{4}$ Algunos éticos del deporte han querido ver este «espíritu del juego» relacionándolo con un «ethos» interno en el deporte. Así pues, Butcher y Shneider entienden que el espíritu o ethos interno del juego se basa en el mismo respeto por el juego. Otros importantes teóricos como Robert Simon hablan de un «ethos interno» que se basa en la defensa de ciertos valores morales internos en el deporte, que van más allá de la letra escrita. Véase. Bucher, R \& Schneider, A. «Fair Play as respect for the game». En Morgan W. J. (Ed) Ethics in Sport. (2001). Champaign (IL). Human
} 
juego que tiene que ser observado y desde donde se entiende que las reglas del juego son elaboradas con el propósito explícito de ayudar en la obtención de una victoria honorable (Keating, 1964, p. 34). Por ello, debemos buscar la equidad, que debe basarse en un tipo de igualdad ante la ley que es necesaria si queremos que la victoria en la competición deportiva tenga validez y sentido.

\section{El sentido ético de la deportividad}

Para garantizar un comportamiento ético en la práctica deportiva y poder aplicar la deportividad como virtud moral, Keating entiende que es necesario aceptar la distinción entre el deporte y el atletismo que -como ya hemos dicho- son dos términos vinculados por un nexo común, pero que se aplican a actividades y objetivos diferentes. De modo que querer aplicar el mismo código moral de conducta a dos formas de actividad distintas, como son el deporte y el atletismo, no sólo es un intento condenado al fracaso, sino que es la consecuencia de un esfuerzo abortivo basado en la proliferación de diversas virtudes morales bajo la bandera de la deportividad. Por ello, distinguir entre ambas actividades es la forma más adecuada de encauzar el problema y llegar hasta la perfección moral, además de ser un antídoto contra este tipo de corrupción moral.

Por tanto, tenemos que aceptar que el verdadero objetivo del deporte debe ser el de determinar la conducta y las actitudes propias de cada participante. En el caso del deporte, el participante deberá fomentar un espíritu de generosidad y magnanimidad, en virtud del cual se tiene que evitar cualquier esfuerzo desagradable que conduzca a situaciones conflictivas, fomentando un espíritu desinteresado y un esfuerzo cooperativo que maximice la alegría del momento (Keating, 1964, p. 34). Mientras que en el atletismo, el objetivo del atleta y su código de conducta debe de ser la búsqueda de la equidad, que es la base del juego limpio y que viene a ser la aplicación de la imparcialidad e igualdad en las reglas del deporte, siendo modesto al recibir la victoria y sereno en la derrota. ${ }^{5}$

Sólo si tenemos presente esta doble aplicación de la deportividad con sus matices, lograremos -según Keating- hacer de la práctica deportiva en sus dos vertientes, algo que está dentro de lo éticamente aceptado.

\section{Deportividad subjetiva u objetiva: La propuesta de Randolf Feezell}

Randolf Feezell en su artículo publicado en 1986 y titulado «Sportsmanship», se preguntaba cómo puede darse una conexión entre las éticas aplicadas y la ética social referidas al deporte, viendo la textura de la experiencia moral individual, junto con la educación moral que hemos recibido, pues resulta evidente que estos factores condicionan (más que determinan) nuestra conducta y nuestra forma de enfrentarnos a la actividad deportiva.

Kinetics. Pág. 22. También. Simon, R (1999). «Internalism and internal values in sport», en Journal of Philosophy of Sport 27.

${ }^{5}$ Posiblemente es ante el horizonte de la derrota en donde tanto el deportista, como cualquier hombre normal, puede sentir temor y frustración. Es por ello, que uno de los más eminentes sociólogos del deporte en España, José María Cagigal, habló de la necesidad y carencia de una pedagogía de la derrota, que todavía está por sistematizar y que posiblemente sea la más profunda y práctica pedagogía que pueda ser escrita. Ciertamente, la derrota como antítesis de la victoria, puede tener dos consecuencias para el sujeto que la experimente, sobre todo aplicada al deporte. En una personalidad preparada, desencadenará nuevas energías, insospechadas habilidades, nos abrirá a nuevos horizontes, robusteciendo nuestra personalidad. Pero en una personalidad endeble que no asimila la derrota, puede producir un cuarteamiento, una gran desilusión que suma al derrotado en un estado de inseguridad consigo mismo que le lleva a recluirse y a no intentar cosas nuevas en el futuro, pues teme volver a fracasar, volver a ser derrotado. Por eso la derrota, dijo Cagigal, es como un veneno, si la dosis es asimilable, se convierte en vacuna, si no se es capaz de asimilarla, puede causar estragos. Cagigal, J. M. (1972). Deporte pulso de nuestro tiempo. Madrid. Editora Nacional. Pp. 73 y ss. 
Feezell adopta un punto de vista aristotélico, quizás influido por el gran redescubridor de Aristóteles en el siglo XX que fue Alasdair MacIntyre, pues al igual que el autor de After virtue, Feezell propone una recuperación de las virtudes en la ética aplicada al deporte. En efecto, Feezell entiende que quizás la ética aplicada tenga que ver con la comprensión de las virtudes individuales que cada sujeto moral tenga que poner en práctica según la actividad que realice. Por ello, para hablar de una ética aplicada al deporte desde la perspectiva propia de las virtudes, Feezell cree oportuno resaltar la función de la virtud llamada deportividad, siendo está una de sus principales aportaciones en el campo de la ética del deporte.

Para Feezell uno de los principales problemas que podemos encontrar en la actividad deportiva -como en cualquier otra forma de actividad humana- es cómo coordinar el punto de vista subjetivo de cada uno de los participantes en el deporte -que obviamente condiciona la forma de realizar una actividad- con una perspectiva objetiva que supondría renunciar a las «apariencias» características de una visión subjetiva en favor de una comprensión más objetiva (Feezell, 2001, pp. 67-83)

Feezell se está refiriendo a uno de las cuestiones más discutidas en filosofía que es la de ver desde donde tenemos concebir la moral, si desde un punto de vista objetivo o subjetivo. En la antigüedad filósofos de la talla de Aristóteles, entendieron que la moral llega al sujeto desde el exterior, defendiendo por tanto una posición objetiva de la moralidad. Pero esta posición que estuvo en vigor durante muchos siglos cambió a partir del siglo XVIII d. de C., cuando entró en escena el filósofo Inmanuel Kant.

En efecto, la filosofía de Kant contribuyó enormemente a cambiar el paradigma vigente de entender la moral. Es por ello que los historiadores de la filosofía han venido llamando a la aportación kantiana «giro copernicano», en honor del astrónomo Nicolás Copérnico a quien debemos el importante cambio que experimentó la astronomía tradicional gracias a la aparición de su obra De revolutionibus orbium caelestium, publicada casi póstumamente (Mínguez, 1987, pp. XL-XLI). La importancia de esta obra radicaba en que Copérnico ofrecía una nueva alternativa a la forma de entender la astronomía, que desde tiempos de Aristóteles y de Claudio Ptolomeo (Mínguez, 2000). Copérnico ofrecía una explicación geocéntrica del universo en donde la tierra se situaba en el centro del cosmos. Copérnico frente al modelo geocéntrico, propuso el modelo heliocéntrico en donde es el sol y no la tierra, quien ocupa el lugar central en el universo y revolucionó la astronomía marcando un referente y una novedad que cambió el pensamiento astronómico.

Si Copérnico logró revolucionar y cambiar la astronomía de su tiempo, también Kant supo revolucionar y cambiar la forma de hacer filosofía. Hasta que Kant entró en escena, se entendía que la moral o el conocimiento le venían al sujeto desde fuera, era una explicación objetiva de la moral y el conocimiento que se remontaba a los tiempos de Aristóteles y que había creado escuela durante el medievo y el pensamiento renacentista. Pero en plena época de las luces, al ilustrado Kant esta explicación no le satisfacía, pues entendía que es el sujeto racional quien establece las condiciones espacio-temporales de la sensibilidad y las categóricas del entendimiento, pero además entiende que es el sujeto moral que es autónomo y fin en sí, quien se da a si mismo las normas morales con la pretensión de que valgan universalmente. ${ }^{6}$

La propuesta de Feezell $(2001,69)$ está plasmando el conflicto entre el sentido subjetivo del valor moral y el sentido objetivo, entendido como un conjunto de normas

\footnotetext{
${ }^{6}$ Recordemos que la formulación del imperativo categórico viene a decir: «obra sólo según una máxima tal que puedas querer al mismo tiempo que se torne ley universal». Kant, I. (1992). Fundamentación de la metafísica de las costumbres. Madrid. Real Sociedad Económica Matritense de Amigos del País. Pág. 55.
} 
convencionalmente aceptadas. ${ }^{7}$ El punto de vista objetivo, puede resultar más atractivo pues nos ofrece un cierto modo de entender el mundo ya que nos ayuda a ir más allá de nuestros propios prejuicios y presupuestos.

Sin embargo, para Feezell (2001, p. 71) el movimiento hacia una perspectiva objetiva de la moral, puede conducirnos a un equívoco en dos sentidos. En primer lugar, la búsqueda de la objetividad nos puede conducir a renunciar a nuestra faceta subjetiva, a nuestro ser particular, a lo que hay de original e irrepetible en nosotros. En consecuencia, una perspectiva objetiva puede arrojarnos a una forma de reduccionismo. Pero en segundo lugar, la visión objetivita puede resultar dañina cuando se vuelca en mostrar nuestras limitaciones epistemológicas y nuestra finitud, pues puede arrojarnos al escepticismo y al nihilismo.

Si nos vamos a una visión subjetiva, encontramos que pese a que desde el exterior de nuestra existencia personal (desde una perspectiva objetiva), ésta aparece como algo pequeño e insignificante, lo cierto es que desde nuestro interior (desde la perspectiva subjetiva) no haber nacido resulta casi inimaginable, mi vida resulta "monstruosamente" importante y mi muerte catastrófica (Nagel, 1986, 209). Para Feezell (2001, p. 70), contemplar el deporte desde un punto de vista subjetivo, puede llevarnos a ver la actividad deportiva como una parte muy importante en nuestra vida y los resultados de dicha práctica, pueden marcar el ritmo de nuestra existencia, haciéndonos ver que nuestra participación en el deporte resulta «monstruosamente» importante y llegar incluso a consumirnos.

Por tanto, una visión subjetiva del deporte puede resultar dañina para quien realice una actividad deportiva, pues se dejaría llevar exclusivamente por su visión personal y por sus deseos e inquietudes propias. Por otro lado, nos encontramos con que una visión objetiva del deporte también puede resultar perjudicial, pues nos podría hacer caer en un reduccionismo o en un escepticismo y nihilismo. Esto nos sitúa en un atolladero para ver desde donde podemos enfocar el deporte como actividad humana y desde qué ética. Si nos referimos al deporte desde el punto de vista subjetivo, nos damos cuenta de que nuestra participación puede resultar monstruosamente importante y llegar a consumirnos totalmente y sin embargo, desde un punto de vista objetivo, el deporte puede parecernos relativamente poco importante.

En el caso del deporte nos encontramos en una paradoja, en donde resulta difícil discernir que postura tenemos que aceptar, si la postura subjetiva o la objetiva, pues parece que tanto la una como la otra tienen algo que decir con lo que decantarnos a favor de una y despreciando la otra podría llevarnos a dejar algún cable suelto.

Si queremos salir de este atolladero, resulta más fácil aceptar que el deporte al igual que la vida misma es un absurdo, entendiendo absurdo de la manera que lo hace Nagel (1979, p. 13) como una notable discrepancia que se produce entre una aspiración y la realidad. Para Nagel la vida misma es un absurdo, pues implica la colisión entre la seriedad en que nos tomamos nuestra vida y la perpetua posibilidad de la diversión, lo arbitrario y lo que está abierto a la duda.

Por ello la solución al problema de ver desde que punto de vista asumir el papel del deporte, no tiene una respuesta fácil e inmediata y esto puede que se deba a que en el fondo tanto en el deporte como en nuestra vida diaria tenemos que vivir con el conflicto sin huir de él.

\footnotetext{
${ }^{7}$ Feezell pone como ejemplo el caso de la política abolicionista llevada a cabo en América por el gobierno del presidente Lincoln y que muestra como a pesar de la objetividad de una norma, que se aplicaría sin excepción en todos los estados de EEUU. Lo cierto es que algunos estados sureños se negaron a aceptar esta medida, debido a intereses económicos, pues su economía se respaldaba en la mano de obra de los esclavos negros, lo que tuvo como desencadenante la Guerra civil. Esto sirve para ver lo difícil que puede resultar aceptar una norma objetiva, pues los criterios subjetivos pueden resultar muy poderosos.
} 
La solución no puede residir en ponernos a favor de un punto de vista y negar el otro, pues entonces estaríamos negando una parte buena del deporte a favor de otra.

Para evitar este tipo de situaciones Feezell (2001, p- 76) opta por decir que el deporte está plagado de una especie de «doble conciencia» en donde ambos puntos de vista (el subjetivo y el objetivo), deben co-existir. Por ello, la conciliación y coexistencia entre los dos puntos de vista, le llevará a afirmar que el deporte debe entenderse como algo irónico, tal y como expondré más tarde.

\section{El problema de la separación entre deporte y atletismo: La Crítica de Feezell a Keating}

Feezell retomó un antiguo debate iniciado por Keating, que para poder abordar el problema de la deportividad como categoría moral, establece la distinción entre deporte entendido como la actividad cooperativa que nos hace pasar del placer a la alegría y que fomenta un espíritu de generosidad y magnanimidad, y el atletismo entendido como una actividad competitiva. Keating entendía que lo importante no es pasarlo bien, sino ganar el encuentro, por eso se caracterizará por un espíritu de dedicación, sacrificio e intensidad.

Como podemos observar, las virtudes deportivas que sigue el que participa en el deporte y el atletismo, son radicalmente diferentes, pues en el caso del deporte, encontramos la cooperación amistosa entre los participantes, mientras que en el caso del atletismo, se trata de una lucha competitiva para obtener la victoria.

Keating (1978, p 143) recurría al siguiente ejemplo para demostrar que las virtudes que se siguen de cada forma de practicar el deporte son distintas en sus participantes. Para ello, nos propone que pensemos en dos equipos que para evitar confusiones llamaremos el equipo $A$ y el equipo $B$.

El equipo A participa en un importante torneo de baloncesto en la escuela y es entrenado por Smith, quien considera que el deporte no es más que una forma de preparación para la guerra y para afrontar con dureza las dificultades de la vida diaria; por ello, el oponente es visto por Smith como un enemigo que debe de ser despreciado y odiado con la finalidad de producir el mayor énfasis y esfuerzo. Para Smith, todo está permitido, incluido un cierto grado de crueldad es su carrera hacia la victoria.

Por el contrario, el equipo B es entrenado por Jones quien -a diferencia de Smith- piensa que no todos los medios (principalmente los considerador ilícitos) valen en la carrera hacia a victoria. Jones también tiene un espíritu cooperativo, pues no duda en infundir a sus jugadores un rendimiento excelente y un afán para que obtengan la victoria. Jones no olvida que el baloncesto (deporte en el que entrena), es ante todo un juego, una actividad arbitraria, inventada con el fin de hacer posible una satisfacción interior y una sensación de alegría que se obtiene por realizar esta actividad.

Visto esto, parecería que los dos entrenadores anteriores tienen actitudes distintas y podríamos pensar que se dedican a actividades diferentes. Es cierto que Smith representaría a un grupo de personas del mundo del deporte que tienen una visión distorsionada de la verdadera función del deporte y que, aunque pueda abundar en los ámbitos deportivos, no quiere decir que este tipo de actitud sea la correcta desde un punto de vista ético. Por este motivo afirma Keating (1978, p. 144) que es la naturaleza de la actividad la que determina la conducta ética, no sólo la actitud personal que tengamos de ella.

El tipo de conducta hacia el deporte que demuestra tener Smith es la que suele generar un comportamiento antideportivo y poco ético; por ello, es imprescindible que sean suprimidas 
del ámbito deportivo. Mientras que la conducta de Jones se acercaría más a la del verdadero significado de la práctica deportiva.

Feezell (1986, p. 155) encuentra dos posibles problemas en la argumentación de Keating. El primero está en que Keating concibe «deporte» haciendo suya la distinción que da Webster sobre el deporte, que lo define como una desviación, diversión y recreación. Definición que para Feezell resulta pobre e incompleta, pues no llega a describir adecuadamente, o más bien describe parcialmente su naturaleza. El segundo, Keating ofrece una falsa exclusividad entre la psicología del deportista y la del atleta. Ciertamente, no se trata de que la mentalidad de un atleta con respecto a la de un deportista sea diferente a la hora de llevar a cabo una actividad deportiva, pues resulta difícil por no decir imposible, pretender determinar las diferencias entre los dos, debido a la complejidad de la mente humana.

Lo cierto es que la actitud de los participantes se mezcla y no hay un patrón determinado que diga de entrada como van a ser sus actitudes. Un jugador puede querer ganar, lograr la victoria. Pero también puede tener un profundo sentimiento que desde lo más profundo de su ser le diga que alcanzar el triunfo está bien, pero no a toda costa, ni utilizando todo tipo de recursos y artimañas que no están dentro de lo éticamente aceptado. No todos los recursos son iguales, ni tampoco ganar el encuentro tiene que ser lo más importante.

Para Feezell (1986, p. 157) la actitud hacia la victoria y hacia la moderación actúa como un control de gravedad que produce moderación. Por ello, la distinción que hace Keating entre deportista y atleta es innecesaria, pues el buen deportista es a la vez buen jugador y atleta. Su propósito es tanto el de ganar la competición como el cooperar para obtener una experiencia lúdica y un placer estético que le lleva a la alegría. Por ello, sus actitudes serán a la vez lúdicas y competitivas.

Feezell asimila también el análisis de Kenneth Schmitz $(1979,22)$, quien entiende que el deporte es principalmente una extensión del juego, que se basa y se deriva de los valores centrales del juego. Al igual que Huizinga en Homo ludens, considera que el juego se entiende como una actividad en donde se participa libremente y que, aunque esté fuera de la vida ordinaria (considerada como lo serio e importante), lo cierto es que también logra absorber intensa y totalmente al jugador.

\section{Deportividad como virtud moral}

Si entendemos que el deporte es una extensión del juego y si la clave de la deportividad es el espíritu del juego, entonces en el deporte deberán darse tanto la parte competitiva como el aspecto cooperativo que nos conduce a una situación placentera y alegre (Feezell, 1986, p. 161). El deporte debiera entenderse como algo serio, pero también como algo divertido y alegre, por ello, deberé estar en una situación intermedia entre las dos partes evitando caer en una posición extrema, pues ver el deporte desde una posición llevada al extremo puede resultar nefasto y tener como consecuencia la aparición de conductas antideportivas.

En efecto, contemplar el deporte desde cualquiera de los extremos puede resultar especialmente perjudicial, si queremos que la práctica deportiva se vea desde lo éticamente aceptable. Para evitar una perspectiva unilateral llevada el extremo Feezell trae a colación la opinión de Kenneth Schmitz (1979, pp. 27-28), para quien la política de ganar a toda costa, es la triste sucesión de la degradación del deporte. El énfasis de la victoria se fija únicamente en el resultado, olvidándose del transcurso del juego, lo que tiene como consecuencia más inmediata que el juego se convierta en una lucha por el poder cuyo resultado es la brutalización del deporte. 
El buen deportista tendrá que combinar tanto la faceta competitiva como la cooperativa, manteniendo a la vez un espíritu de amistad sin renunciar a su pretensión de alcanzar la victoria. En consecuencia, el buen deportista tendrá que evitar insultar o lastimar a su oponente ya que tal y como sugiere Feezell- un jugador puede representar una comprensión de la justicia a través de la relación que mantiene con su oponente, pues le toca competir con otros que le desafían a ser mejores (Feezell, 2001, p. 78). Por ello, deberán mostrar respeto por su adversario, ya que, sin él, sería imposible el logro de la excelencia moral, pues sin otros actores que desempeñan el mismo papel que yo en el terreno de juego y que me desafían en mi carrera hacia la victoria, no podría sacar mis propias habilidades adquiridas en años de entrenamiento y no tendría la oportunidad de aplicar las reglas del deporte junto con sus restricciones. Otros importantes representantes de la ética contemporánea del deporte, como Warren P. Fraleigh (1984, pp. 8789) defienden la importancia de ver al oponente como facilitador y no como obstáculo. Concluyendo que, pese a cualquier tipo de dificultad que encontremos, la posición del oponente como facilitador es la que más se aproxima al bien de todos, desde un punto de vista moral. Pues como añade Jesús Conill (2006, p. 179): en el fondo compartimos el deseo de lo justo y nos sentimos afectados por un sentimiento de pertenencia que nos vincula al otro.

Nuestra actividad en la competición deportiva deberá ejercitarse en el autocontrol y el parentesco con el oponente, maximizando los posibles valores morales que se derivan del terreno de juego y haciendo de la deportividad una virtud moral basada en un término medio entre lo serio y lo divertido, entre una actitud competitiva y cooperativa, pues como nos enseñó Aristóteles la virtud es el término medio entre el exceso y el defecto (Et a Nic. 1106 b).

\section{Jugando irónicamente}

Llegados a este punto, nos quedaría ver cual debe de ser la actitud más adecuada para entender y participar en el deporte. Para Feezell la actitud más adecuada para el deporte debe de ser la ironía, entendida no en el sentido socrático, es decir, en la manera que tenía Sócrates de hacer que su contrincante en el diálogo se diera cuenta de su propia ignorancia, haciéndole ver que aunque pretende saber mucho en realidad no sabe nada (Rep. I, 337 a). En este contexto, debe entenderse ironía como un sentimiento de la vida o más concretamente como un talante ${ }^{8}$ que es como la entiende Harald Höffding (Ferrater Mora, 1994, p. 1903).

En efecto, Feezell (2001, p. 77) entiende la ironía como un talante o forma de participación en el deporte que incluye tanto la búsqueda de la excelencia atlética y el deseo de la victoria, como la seriedad y la trivialidad que se dan en el deporte. La ironía aplicada al deporte es una actitud que abarca la incongruencia de la inclinación del ser humano por lo trivial y lo absurdo, con su deseo de jugar en serio. Como sostiene al respecto José María Cagigal (1972, p. 120) el deporte, aunque es una realidad eminentemente competitiva, sigue siendo primariamente un juego, es decir, en el deporte se combinan dos aspectos del hombre como son la seriedad, por el afán de la victoria, y su ansia de diversión.

El competidor irónico, tal y como lo califica Feezell, es capaz de combinar la seriedad con la alegría; por ello, la ironía en este contexto, no es más que un estado de ánimo a medio camino entre la seriedad y el juego. El competidor irónico puede combinar una actitud de humildad sin abandonar su pretensión de competir, comportándose correctamente ante los éxitos cosechados.

La visión irónica del deporte, no priva a éste de la posibilidad de competir, ya que la competencia es un componente esencial para el deporte y ofrece a los participantes la

\footnotetext{
${ }^{8}$ Entiendo «talante» como disposición personal.
} 
posibilidad de adquirir una serie de bienes internos gracias a su participación. Ahora bien, la perspectiva de la competición, no es el único componente que debe darse en la práctica deportiva, pues a ello debemos sumar la posibilidad de divertirnos con nuestra participación en el deporte, lo que nos ayudará a romper con la excesiva seriedad del encuentro deportivo y la obsesión por conseguir la victoria. No debemos olvidar que toda competición deportiva, está acompañada por el espectro del fracaso y la derrota, que puede resultar peligrosa, ya que puede causar el cuarteamiento de la persona que fracasa. Es bueno que en la competición deportiva se cultiven las dos perspectivas, tanto la competitiva que da a nuestra participación en el encuentro un componente de seriedad, como la divertida que hace que el afán por la victoria no sea el único objetivo a perseguir y que ayuda a que nuestra hipotética derrota no se convierta en una experiencia especialmente traumática.

La competición deportiva desde la óptica de la ironía, se convierte para el que participa en el deporte, en un desafío para ser mejor, frente a otros sin los cuales no sería posible el juego. Para Feezell garantiza el respeto hacia el adversario que debe desarrollarse en la competición deportiva en todo momento, pues sin los adversarios no podríamos competir y demostrar nuestras habilidades competitivas.

Por ello para Feezell (2001, p. 78), el deporte es un buen ámbito para mostrar y desarrollar la excelencia y el buen carácter moral (êthos), dentro de este desarrollo se incluirían las actitudes de respeto a los oponentes, a los entrenadores, funcionarios y al propio juego. Como dicen Robert Butcher y Angela Schneider (2001, p. 22): el espíritu del juego, pues el juego limpio consiste precisamente en respetar ese espíritu interno que se da en el deporte, Solo así haremos posible lo imposible que el deporte y su práctica entre dentro de lo éticamente aceptable. ¿Para qué sirve la ética? En este caso y en otros, serviría para intentar forjarse un buen carácter que aumente la probabilidad de ser felices y justos, al ayudar a estimar los mejores valores y optar por ellos como ha sugerido Adela Cortina, $(2014,46)$.

\section{Conclusión}

Keating es uno de los autores pioneros que impulsaron la andadura de la futura filosofía y ética del deporte al haber defendido que la deportividad debe ser entendida como categoría moral. De este modo se unió a la tradición iniciada por el barón de Coubertin. Para este autor resultaba esencial que el deportista desarrollara cualidades morales tan loables como el coraje, el autocontrol, la cooperación y un espíritu saludable de búsqueda del honor; pero, sobre todo, debería poseer dos ingredientes fundamentales en su conducta, que son la generosidad y la magnanimidad, pues estas dos son las que fomentan el esfuerzo cooperativo, para que la actividad lleve del placer a la alegría. Esto demuestra que el código que rige el deporte es sustancialmente diferente a un código legalista, como el que es utilizado por los tribunales de justicia o los abogados. El código del deporte tiene como objetivo principal el de proteger y cultivar el buen estado de ánimo y fomentar el carácter festivo característico de este tipo de actividad humana, cuya única finalidad debe de ser la de proporcionar una diversión agradable a sus participantes.

Para garantizar un comportamiento ético en la práctica deportiva y poder aplicar la deportividad como virtud moral, Keating entendió que era necesario aceptar la distinción entre el deporte y el atletismo. En el caso del deporte, el participante deberá fomentar un espíritu de generosidad y magnanimidad, en virtud del cual se tiene que evitar cualquier esfuerzo desagradable que conduzca a situaciones conflictivas, fomentando un espíritu desinteresado y un esfuerzo cooperativo que maximice la alegría del momento. Mientras que, en el atletismo, el objetivo del atleta y su código de conducta debe de ser la búsqueda de la equidad, que es la base del juego limpio y que viene a ser la aplicación de la imparcialidad e igualdad en las reglas del deporte, siendo modesto al recibir la victoria y sereno en la derrota. 
Feezell cree oportuno resaltar la función de la virtud llamada deportividad, siendo está una de sus principales aportaciones en el campo de la ética del deporte; pero entiende como innecesaria la distinción entre la aplicación de la deportividad al deporte y al atletismo. Feezell opta por decir que el deporte está plagado de una especie de «doble conciencia» en donde ambos puntos de vista (el subjetivo y el objetivo), deben co- existir. En la actitud de los participantes se mezcla en el terreno deportivo y no hay un patrón determinado que diga de entrada como van a ser sus actitudes. Un jugador puede querer ganar, lograr la victoria; pero también puede tener un profundo sentimiento que desde lo más profundo de su ser le diga que alcanzar el triunfo está bien, pero no a toda costa, ni utilizando todo tipo de recursos y artimañas que no están dentro de lo éticamente aceptado. No todos los recursos son iguales, ni tampoco ganar el encuentro tiene que ser lo más importante.

Para Feezell la actitud hacia la victoria y hacia la moderación actúa como un control de gravedad que produce mesura en el terreno deportivo. Contemplar el deporte desde cualquiera de los extremos puede resultar especialmente perjudicial, si queremos que la práctica deportiva se vea desde lo éticamente aceptable. Para evitar una perspectiva unilateral llevada al extremo, Feezell trae a colación la opinión de Kenneth Schmitz, para quien la política de ganar a toda costa es la triste sucesión de la degradación del deporte. El énfasis de la victoria se fija únicamente en el resultado olvidándose del transcurso del juego, lo que tiene como consecuencia más inmediata que el juego se convierta en una lucha por el poder, cuyo resultado es la brutalización del deporte.

El buen deportista tendrá que combinar tanto la faceta competitiva como la cooperativa, manteniendo a la vez un espíritu de amistad sin renunciar a su pretensión de alcanzar la victoria. Por ello, deberá mostrar respeto por su adversario, ya que, sin él, sería imposible el logro de la excelencia moral, pues sin otros actores que desempeñan el mismo papel que yo en el terreno de juego y que me desafían en mi carrera hacia la victoria, no podría sacar mis propias habilidades adquiridas en años de entrenamiento y no tendría la oportunidad de aplicar las reglas del deporte junto con sus restricciones.

Para Feezell la actitud más adecuada para el deporte debe de ser la ironía, entendida no en el sentido socrático, es decir, en la manera que tenía Sócrates de hacer que su contrincante en el diálogo se diera cuenta de su propia ignorancia, haciéndole ver que, aunque pretende saber mucho en realidad no sabe nada. Sino que, en este contexto, debe entenderse ironía como un sentimiento de la vida. Feezell entiende la ironía como un talante o forma de participación en el deporte, que incluye tanto la búsqueda de la excelencia atlética y el deseo de la victoria, como la seriedad y la trivialidad que se dan en el deporte. El competidor irónico puede combinar una actitud de humildad sin abandonar su pretensión de competir, comportándose correctamente ante los éxitos cosechados. La competición deportiva, desde la óptica de la ironía, se convierte para el que participa en el deporte, en un desafío para ser mejor, frente a otros sin los cuales no sería posible el juego. Ya que el deporte no debe centrarse exclusivamente en la ganancia desmedida, pues como ya dijera Juvenal (Sátira X, 104):

«el que anhelaba honores desmedidos, y reclamaba desmedidas riquezas, preparaba numerosos pisos de una torre encumbrada, desde donde más alta fuese la caída y fenomenal el batacazo de aquellos escombros venidos abajo» 


\section{Bibliografía}

- Aristóteles. (1999). Ética a Nicómaco. Madrid: CEPC.

- Bergson, H. (1912). Le Gaulois littéraire, citada por Carretón, P. (1985). Les fêtes du corps. Université de Saint Etienne.

- Butcher, R \& Schneider, A. "Fair Play as respect for the game". En Morgan W. J. (Ed) Ethics in Sport. (2001). Champaign (IL): Human Kinetics.

- Bryson, L. (1947). Science and freedom. New York: Columbia University Press.

- Cagigal, J. M. (1972). Deporte pulso de nuestro tiempo. Madrid: Editora Nacional.

- Camus. A. (1951). Resistance, Rebellion and Death. New York: Alfred A. Knopf, Inc.

- Cortina, Adela. (2014). ¿Para qué sirve realmente la ética? Barcelona: Paidos.

- Conill, J. (2006). Ética hermenéutica, Madrid: Tecnos.

- De Coubertin, Pierre. (1973). Ideario olímpico: Discursos y ensayos. Madrid: Instituto Nacional de Educación Física.

- Dell, Aquila, P; Zurla, P. (Eds). (2005). Sport e società: contributi multidisciplinari. Cesena: Società Editrice "Il Ponte vecchio".

- Feezell, R. (2017). Laying Games: An Introduction to the Philosophy of Sport Through Dialogue. London: Routledge.

- Feezell, R. (2013). Sport, Philosophy, and Good Lives. Lincoln: University of Nebraska Press. https://doi.org/10.2307/j.ctt1ddr7rd

- Feezell, R. (2001). Sport and the view from nowhere. Journal of the Philosophy of Sport. 28: 1-17. https://doi.org/10.1080/00948705.2001.9714597

- Feezell, R. (1986). Sportsmanship. Journal of the Philosophy of Sport. 13:1-13. https://doi.org/10.1080/00948705.1986.9714436

- Ferrater Mora, J. (1994). Diccionario de filosofía II. Barcelona: Editorial Ariel.

- Fraleigh, W. P. (1984). Right actions in sport. Champaign: Human Kinetics publishers.

- García Ferrando, M. (1990): Aspectos Sociales del Deporte. Una reflexión sociológica. Madrid: Alianza Editorial.

- García Ferrando, M. (2005). Sociología del deporte. Madrid: Alianza Editorial.

- Guttmann, Allen. (1978). From ritual to record: the nature of modern sport. New York: Columbia University Press. 
- Guttmann, Allen. (2000). "Development of Modern Sport", Coakey, J. \& Dunning, E. Handbook of Sport Studies. London: Sage. https://doi.org/10.4135/9781848608382.n15

- Illundáin-Agurruza, J. (2014). José Ortega y Gasset: Exuberant Steed, Sport, Ethics and Philosophy, 8: 285-314. https://doi.org/10.1080/17511321.2014.981361

- Juvenal. (1996). Sátiras. Madrid: C.S.I.C.

- Kant, I. (1992). Fundamentación de la metafísica de las costumbres. Madrid: Real Sociedad Económica Matritense de Amigos del País.

- Keating, J, (1964). Sportsmanship as a moral category. Ethics, LXXV. 25-35. https://doi.org/10.1086/291517

- Keating, J. (1978). Competition and Playful Activities. Washington: University press of America.

- Leahy, F. (1951). Defensive football. New York: Prentice Hall, Inc.

- López Frias, F. J. (2016). The Reconstructive and Normative Aspects of Bernard Suits's Utopia, Reason Papers. 38, 51-64.

- MacIntyre, A. (1981). After virtue. Indiana: University of Notre Dame Press.

- MacIntyre, A. (1972). Predictability and Explanation in the Social Sciences, Philosophic Exchange. 1. 5-14.

- McNamee, M. (2007). Sport, Ethics and Philosophy: Context, history, prospects. Sport, Ethics and Philosophy. 1. 1-6. https://doi.org/10.1080/17511320601173329

- Mínguez Pérez, C. (2000). Ptolomeo (Siglo II d.C.). Madrid: Ediciones del Orto.

- Mínguez Pérez, C. (1987). "Estudio preliminar”. En Copérnico, N. Sobre las revoluciones. Madrid: Tecnos.

- Morgan, W. (Ed). (2007). Ethics in Sport. Champaign, IL: Human Kinetics.

- Nagel, T. (1986). The view from nowhere. New York: Oxford University Press.

- Nagel, T. (1979). Mortal Questions. Cambridge: University Press.

- Ortega y Gasset, J. (1983). "El origen deportivo del Estado". Obras completas. 2. Madrid: Alianza Editorial.

- Platón. (1998). República. En Diálogos IV. Madrid: Biblioteca Clásica Gredos.

- Simon, R. L. (1999). Internalism and internal values in sport, Journal of the Philosophy of Sport, 27, 1-16. https://doi.org/10.1080/00948705.2000.9714586

- Suits, B. "The Elements of Sport". En Morgan, W. J. (Ed). (2007). Ethics in Sport. Champaign (IL): Human Kinetics. 
- Suits, B. (2005). The Grasshopper: Games, Life and Utopia. Ontario: Broadview Press.

- Schmitz, K. (1979). "Sport and play: Suspension of the Ordinary". Sport and the body: A Philosophical Symposium. Philadelphia: Lea \& Febiger.

- Wittgenstein, L. (2001). Philosophical Investigations, Oxford: Blackwell.

- Weis, P. (1969). Sport: A philosophical inquiry, Southern Illinois University Press. 